\title{
THE IMPACT ANALYSIS OF MOTIVATION, TRAINING, AND WORK ENVIRONMENT TO NURSES PERFORMANCE IN PATIENT SAFETY
}

\author{
Fushen $^{1}$, and Meylona Verawaty Zendrato ${ }^{2}$ \\ 1,2 Nursing Program, Akademi Kesehatan Swakarsa Jakarta \\ Jakarta, Indonesia \\ dr.fushen@ukrida.ac.id,meylona89@gmail.com ${ }^{1}$
}

\begin{abstract}
The development of hospitals in health industry as economic institutions and the establishment of many new hospitals increase the number of nurses needed while the number of nurses produced cannot keep pace with the increasing demand. In hospital services, nurse is the most frequently interacted person with patients and are fully responsible for patient care, including in terms of patient safety. This study aims to obtain empirical evidence about the effect of motivation, training and work environment on the performance of nurses in patient safety in the Public Hospital. Expected output from this study can be used as a reference to determine the policy for nurse management at the hospital. This is a correlational analytic study with a cross-sectional approach and descriptive method of verification. The research was conducted in a Public Hospital in Jakarta. The research sample are 90 nurses working in inpatient wards. The hypothesis of this study were analyzed with path analysis methods. The results of this study showed a significant positive effect between motivation and performance $(20.7 \%)$, training and performance $(21.8 \%)$, working environment and performance $(20.7 \%)$, and the simultaneous influence from motivation, training, and working environment on the performance $(63.2 \%)$.
\end{abstract}

\section{Keywords: motivation, training, work environment, patient safety.}

\section{Introduction}

The development of the health world in the city is inseparable from the changing function of the Hospital from a social institution into an economic institution, namely with the development of hospital institutions that are more directed and more oriented to "business", especially after allowing investors to establish hospitals under legal entities which aims to make a profit (Vansant 2016). Basically the profession of doctors is not a business profession, but is a profession that must be carried out with morality because it must always be ready to provide help to those who need it. However, with this change, the medical profession which has professional autonomy or independence in carrying out its profession also begins to experience a shift due to the interests of the Hospital as an institution involving investors and the purpose of gaining profits.
In overcoming the problems arising from the shifting of the hospital paradigm from the principle of giving help to being profit-oriented the government made several policies. One of them is by making Law Number 44 of 2009 concerning Hospitals. The regulation emphasizes that hospitals are health care institutions based on humanity so they must prioritize patient safety compared to financial benefits. In addition, hospitals must also provide quality and safe services.

Health services in hospitals have developed as risk-dense services. When a patient enters a hospital, he will undergo various medical procedures, interact with many doctors, nurses, pharmacists, pharmacist assistants, nutrition departments, laboratory officers, radiology officers and others (Dekker 2016). Errors can occur in each part of it. Based on this, the hospital is directed to continue providing health services to the people in need, especially for the poor. 
This shows that the government is trying to keep hospitals providing services based on humanity. Based on these obligations the hospital is also directed to provide security for individuals who work in hospitals and patients served. In carrying out a patient safety program, the government has issued guidelines in the Minister of Health Regulation No. 1691 of 2011 concerning Hospital Patient Safety. In carrying out its work, every employee needs good motivation to produce good performance. This also applies in the field of hospital. Motivation has an important role in shaping behavior, and specifically, in influencing work performance in organizations.

Changes that occur in the health industry certainly require hospital organizations to adjust to these changes (Harrison, Cohen, and Walton 2015). In establishing a culture of patient safety in hospitals, nurses are employees who play a key role because they are directly related to patients (Elsheikh et al. 2017). To improve performance, training for nurses is needed, including in patient safety. Training is a systematic change of knowledge, skill, attitude, and behavior that continues to experience improvement that every employee has with it can realize the goals to be achieved by an organization or company in fulfilling desired HR standards.

Employees in a hospital, especially nurses, have different jobs with employees in the company in general (Sommers et al. 2018). Nurses in carrying out their work interact a lot with patients and other employees. This certainly creates a different risk compared to employees in general. Employees need a work environment that supports personal comfort and enables good performance, in accordance with what was stated by Langton and Robbins, "employees want work environment challenges that support personal comfort and job performance." (Langton, Robbins, and Judge 2016)
In hospital services, nurses are people who most often interact with patients and are fully responsible for patient care. With the development of the hospital industry as an economic institution and the establishment of many new hospitals, the number of nurses' needs has increased while the production of the number of nurses has not been able to keep pace with the increasing demand (Gunawan and Aungsuroch 2015). Therefore, hospitals need to calculate nurses' needs well and have the right utilization strategy.

At present the needs of the number of nurses cannot be determined precisely through various existing theories. Likewise with the strategy of utilizing nurses that can vary in each hospital. The development of hospitals is now oriented towards patient safety. Nurses who are the biggest component in human resources in hospitals, and people who interact with patients most often have a very important role in forming a patient safety culture (DiCuccio 2015).

The establishment of a patient safety culture will certainly experience some obstacles and problems when applied. Hospital performance in general will be determined by nurse performance which is very likely influenced by nurse motivation and work environment (Ma, Olds, and Dunton 2015). One effort to improve nurse performance can be done by holding training for nurses.

Public hospital is serving a large number of patients with a limited number of nurses. The gap in the quantity and quality of nurses with the number of patients served will affect the high workload of nurses. Workload and income and opportunities for achievement are things that play a role in forming motivation (Sutarto, Joebagio, and Pawito 2016). The existence of a characteristic picture that shows gaps in the quantity and quality of nursing staff at the Public hospital is something that 
needs special attention and can be investigated for its effect on performance.

Patient safety training has been conducted in public hospitals in accordance with patient safety standards for nurses which include patient identification, effective communication, drug administration, safety of surgical procedures, infection prevention and control, and prevention of patients falling.

High workload, different patient characteristics, training provided, and hospital environment have an effect on patient safety. Problems in identifying patients and administering drugs can occur due to the large number of patients and the high workload. Effective communication can be a problem when health workers are faced with patients with different characteristics. Security in surgical procedures can occur if health personnel do not follow the prescribed standard operating procedures. A patient safety culture that is new in the world of health often experiences problems in infection prevention and control, especially in terms of hand washing habits, often health workers do not wash their hands after providing services from one patient to another. Falling patients are also a problem that often occurs due to a lack of awareness in this regard.

Assessment of nurses 'performance in public hospitals is carried out regularly by using the List of Job Implementation Assessments (DP3) and List of Nurses' Work Appearances (Performance Appraisal). Average nurses' performance at Public hospital based on the assessment carried out included in the medium category (13-14.5 of a total maximum score of 15). Specific assessments for nurse performance in terms of patient safety are not routinely carried out. Therefore, this study can be useful as an evaluation of nurse performance in patient safety.
This study seeks to find the effect of motivation, training and nurse work environment on nurse performance in patient safety at Public hospital. It is expected that the output of this study can be used as a reference material to determine the policy of utilizing nurses in hospitals.

Some of the problems identified are lower public hospital nurse salaries compared to private hospitals, high workloads, hospital policies that limit professional autonomy, training that does not guarantee the expected results, patient safety training that cannot be measured, work environment different from private hospitals, lack of security systems, patients with different characteristics, cooperative relationships between nurses and doctors often become problems in health services, many standard operating procedures are often not implemented properly, awareness of patient safety has not become a culture in some hospitals in Indonesia, patient safety requires cross-field collaboration.

Based on existing problems, the problems studied were about motivation, training, work environment, and performance of nurses in public hospital. In addition, this study also measured how much influence each variable had on nurses' performance in the safety of patients in public hospital.

The purpose of this study was to find out and conduct an analysis of the conditions of motivation, training, work environment, and performance of nurses in public hospital. In addition, this study also analyzes the influence of each variable on nurse performance in patient safety in public hospitals and formulates the relationship between motivation, training, and nurse work environment on nurse performance in the safety of patients in public hospital. This research is expected to be a reference for setting appropriate policies for hospitals and becoming an initial research to develop further complex research. 


\section{Theoretical Framework}

The relationship between motivation and training can be seen from one of the benefits of training and development programs, namely to create attitudes, loyalty, and cooperation that are more profitable and help employees in their personal improvement and development. While training provides benefits in increasing one's career path and helping to develop solutions for future responsibilities. The work environment also influences motivation. The organization's efforts to increase employee morale are not only based on motivation but also a work environment that supports all activities in carrying out daily operational activities (Olds et al. 2017). A good organizational work environment will lead to comfort and peace in work so that it becomes a driving force for employees to work more energetically. Conversely, a poor workplace health environment can reduce the health and work power of employees.

In addition to influencing motivation, the work environment also has a relationship with training. Training is the best step in preventing or reducing the occurrence of workplace accidents in a company so that it will create a calm, safe working atmosphere and stability in their mental attitude. One form of influence of training on the work environment is a form of outside training which can be an opportunity for refreshing the work atmosphere. DeCenzo and Robbins explained, "The function of the human resource management process," motivation has a core role in shaping behavior, and specifically, in influencing job performance. in the organization (Robbins, S. P., DeCenzo, D. A., and Coulter 2017).

Besides being influenced by motivation, performance is also influenced by training (Xie et al. 2017). This is reflected in Wayne F. Cascio's opinion, training consists of planned programs planned to improve performance at the individual, group and organizational levels (Wayne and Herman 2017). Improve performance that can be measured by changes through knowledge, skills, attitudes and social behavior of employees. Gary Dessler states that training plays an important role in the performance management process (Dessler 2017). Environment is also one of the factors that affect performance. This is consistent with Langton and Robbins's statement, "employees want work environment challenges that support personal comfort and job performance." (Langton, Robbins, and Judge 2016)

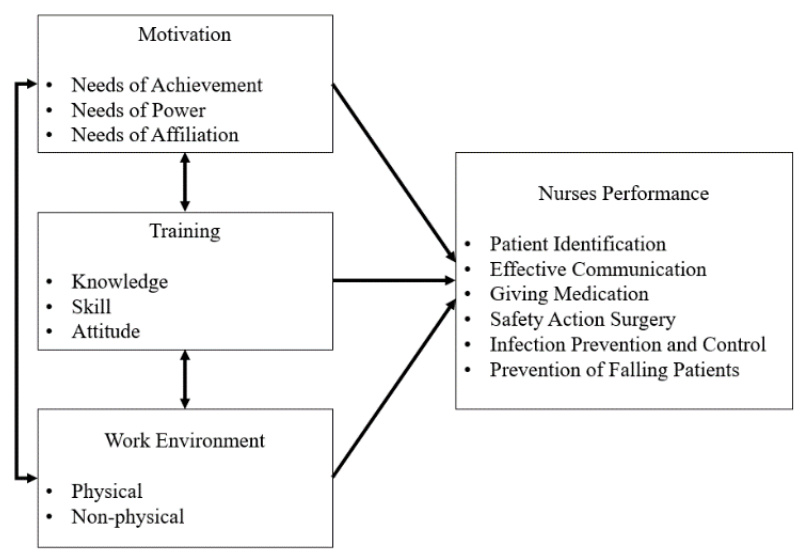

Figure 1. Theoretical Framework

Based on the theoretical framework, this research start with some hypothesis:
1. There is a significant effect of nurse motivation on nurse performance in patient safety at public hospital 
2. There is a significant effect of nurse training on nurse performance in patient safety at public hospital

3. There is a significant influence on the work environment of nurses on nurse performance in patient safety at public hospital

4. There is a significant effect of motivation, training, and nurse work environment on nurse performance in patient safety at public hospital

\section{Methodology}

The research conducted is correlational analytic research using cross-sectional design with verified descriptive objectives, namely research that basically wants to test the truth of a hypothesis that is carried out through collecting data in the field at a certain time, which in this study will test motivation, training and the nurse's work environment towards nurse performance in establishing a patient safety culture. This study uses path analysis techniques to see firsthand the effect of independent variables on the dependent variable.

The smallest observation unit in this study was a nurse in an inpatient installation. The location of the study was conducted at a public hospital in Jakarta. This hospital has a capacity of 560 beds, is accredited, and is a referral hospital. The number of nurses is 652 people. The research was conducted at this public hospital because it is one hospital with a good nursing culture and complete data. This public hospital also has a working environment that is different from the hospital in general because it applies the Green Hospital policy.

Independent variables in this study are (1) Motivation, is an impulse that arises in a person to move and direct behavior; (2) Training, is an activity that aims to develop the knowledge, skills and attitudes of employees; and (3) Work environment, is an environment where employees carry out tasks and daily work. Dependent variable in this study is nurse's performance in patient safety which is defined as an output produced by the functions or indicators of a job or a profession in a certain time. Confounding variables in this study were Age, Gender, and Education Level

Table 1. List of Variables, Dimensions, and Indicators

\begin{tabular}{|c|c|c|}
\hline Variable & Dimension & Indicator \\
\hline \multirow{4}{*}{ Motivation } & Needs of & 1.Job satisfaction \\
\hline & Achievement & 2. Performance achievement \\
\hline & Needs of Power & $\begin{array}{l}\text { 1. Self-development } \\
\text { 2. Professional autonomy }\end{array}$ \\
\hline & $\begin{array}{l}\text { Needs of } \\
\text { affiliation }\end{array}$ & $\begin{array}{l}\text { 1. Comfort at work } \\
\text { 2. Good relations with coworkers }\end{array}$ \\
\hline \multirow[t]{3}{*}{ Training } & Knowledge & $\begin{array}{l}\text { 1. Suitability of training } \\
\text { 2. Additional knowledge }\end{array}$ \\
\hline & Skill & $\begin{array}{l}\text { 1. Suitability of training } \\
\text { 2. Additional skill }\end{array}$ \\
\hline & Attitude & $\begin{array}{l}\text { 1. Service responsibilities } \\
\text { 2. Friendliness }\end{array}$ \\
\hline $\begin{array}{l}\text { Work } \\
\text { Environment }\end{array}$ & $\begin{array}{l}\text { Physical } \\
\text { environment }\end{array}$ & $\begin{array}{l}\text { 1. Lighting system } \\
\text { 2. Temperature and air circulation } \\
\text { 3. Environmental Safety }\end{array}$ \\
\hline
\end{tabular}




\begin{tabular}{|c|c|c|}
\hline & $\begin{array}{l}\text { Non-physical } \\
\text { environment }\end{array}$ & $\begin{array}{l}\text { 1. Work relations with nurses } \\
\text { 2. Work relations with doctors }\end{array}$ \\
\hline Nurses & Patient & 1. Minimum 2 patient identities \\
\hline \multirow[t]{11}{*}{ Performance } & Identification & 2. Name bracelets \\
\hline & Effective & 1. Writing down \\
\hline & communication & 2. Readback and hearback \\
\hline & Giving & 1. Drugs Allergy \\
\hline & Medication & 2. Drugs storage \\
\hline & Safety Action & 1. Verification before surgery \\
\hline & Surgery & 2. Informed consent \\
\hline & Infection & 1. Indications for hand washing \\
\hline & $\begin{array}{l}\text { Prevention and } \\
\text { Control }\end{array}$ & 2. Proper hand washing steps \\
\hline & Prevention of & 1. Repeat review \\
\hline & Falling Patients & 2. Reporting the patient falls \\
\hline
\end{tabular}

In this research, the study population was nurses in the inpatient ward at public hospital. The study sample was nurses in the inpatient ward at public hospital that met the inclusion criteria (1) nurses who work in the inpatient ward at public hospital; and (2) willing to be a respondent. While the exclusion criteria is nurses who are on leave.
The characteristics of the respondents in this study were homogeneous, so the sampling technique used was simple random sampling. The minimum number of samples is determined by calculating the number of samples for correlation analysis:

$$
\begin{aligned}
& \mathrm{N} \text { minimum }=\frac{(\mathrm{Z} \alpha+\mathrm{Z} \beta)^{2}}{\{0.5 \ln ((1+\mathrm{r}) /(1-\mathrm{r}))\}^{2}}+3 \\
& \mathrm{n}=\text { sample size } \\
& \mathrm{Z}=\text { deviation } \mathrm{Z} \text { obtained from the standard normal distribution table } \\
& \alpha=\text { confidence level }=95 \% \quad 1-\alpha=95 \% \quad Z \alpha=1.96 \\
& \beta=\text { test power }=80 \% \quad 1-\beta=80 \% \quad Z \beta=0.84 \\
& \mathrm{r}=\text { correlation coefficient }=0.3 \\
& \mathrm{n} \text { minimum }=\frac{(1.96+0.84)^{2}}{\{0.5 \ln ((1+0.3) /(1-0.3))\}^{2}}+3 \\
& \mathrm{~N} \text { minimum }=84.835=85 \\
& \mathrm{n} \text { questionnaire }=\quad 1.15 \times \mathrm{n} \\
& \mathrm{n} \text { questionnaire }=\quad 1.15 \times 85=97.75=98
\end{aligned}
$$

The types of data needed in this study are primary data and secondary data. In this study the primary data was obtained using a structured questionnaire made on a Likert Scale and given to the selected respondents. Secondary data used is the number and characteristics of inpatient nurses at public hospital.

Based on the method used in data collection, the variables that have ordinal size are then transformed into the form of intervals with the Successive Interval 
Method. The analytical methods used are univariate analysis using descriptive statistics, bivariate analysis using correlation analysis, multivariate analysis using multiple regression, and influential analysis using path analysis.

Descriptive analysis of each variable will be classified by category:

Table 2. Category for Each Variables

\begin{tabular}{cc}
\hline Score & Category \\
\hline $1,00-1,80$ & Very Low \\
\hline $1,81-2,60$ & Low \\
\hline $2,61-3,40$ & Medium \\
\hline $3,41-4,20$ & High \\
\hline $4,21-5,00$ & Very High \\
\hline
\end{tabular}

Analysis in processing data through Path Analysis, namely by looking at the magnitude of the influence of the variables of motivation, training, and work environment on nurse performance variables at Public hospital as shown in the picture below:

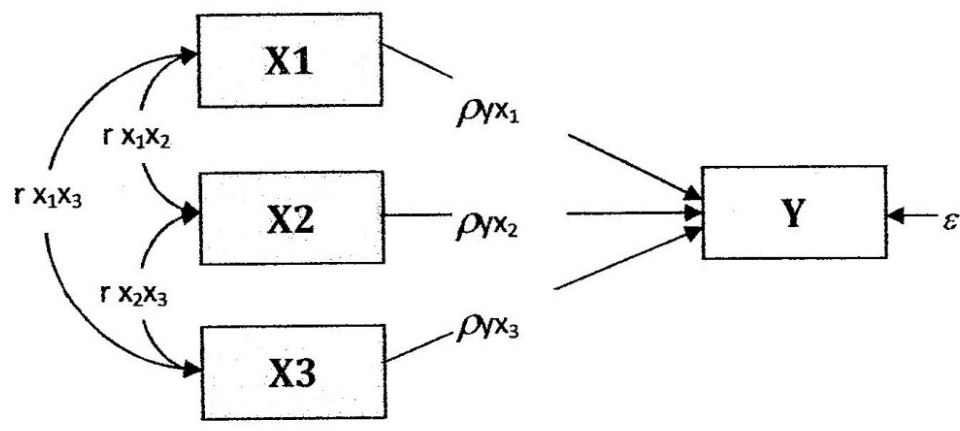

Figure 2. Path Equation Model

Path equation $=\mathrm{Y}=\rho_{\mathrm{YX} 1} \cdot \mathrm{X} 1+\rho_{\mathrm{YX} 2} \cdot \mathrm{X} 2+\rho_{\mathrm{YX} 3} \cdot \mathrm{X} 3+\varepsilon$

$\mathrm{X}_{1} \quad$ : Motivation

$\mathrm{X}_{2} \quad$ : Training

$\mathrm{X}_{3} \quad$ : Work environment

$\mathrm{Y} \quad$ : Performance

$\varepsilon \quad:$ Other variable outside the model

$\rho_{Y X i} \quad$ : The magnitute of $X_{i}$ influence on $Y$

$\mathrm{r}_{\mathrm{a}} \mathrm{X}_{\mathrm{b}} \quad$ : The magnitute of $\mathrm{X}_{\mathrm{b}}$ influence on $\mathrm{X}_{\mathrm{a}}$

\section{Result and Discussion}

The capacity of beds for public hospitals in 2009 and 2010 was 504 beds, while the number of nurses in 2009 was 659 and in 2010 there were 647 people. In 2011, public hospital bed capacity increased to 586 beds, but the number of nurses was reduced to 645 people.

There are gaps in the quality of nurses in Public hospitals Number of professionals
(Bachelor of Nursing Nurses \& Masters in Nursing) 47 people $(7.29 \%)$, while vocational staff (School of Health Nursing, Diploma III Nursing and Midwifery and Dental, D IV Nursing, Midwifery and Dental and Bachelor of Nursing without profession) as many as 598 people $(92.71 \%)$. Nursing staff Public hospitals are dominated by $25-30$ year olds with $45 \%$. 
Public hospital has several training programs for nursing staff inside and outside Public Hospital. The assessment of the performance of nurses at the Public hospital is carried out periodically by using the List of Job Implementation Assessments (DP3) and List of Nurses' Work Appearances (Performance Appraisal).

Based on the results of data collection through questionnaires to nurses in inpatient wards Public hospitals were made as respondents, out of 98 questionnaires distributed, only 90 questionnaires were filled in completely and could be processed, so the number of research samples in this study were 90 respondents (number of samples minimum is 85 respondents). The characteristics that can be presented in this study include: gender, age of the respondent, last formal education, and the tenure of the respondent.

Table 3. Respondent's Characteristics

\begin{tabular}{llrr}
\hline Characteristic & Number & Percentage \\
\hline Sex & Male & 8 & \\
& Female & 82 & 9,9 \\
& Total & 90 & 100 \\
\hline Age & & \\
& $<25$ years & 11 & 12,2 \\
25-35 years & 50 & 55,6 \\
$>$ 35 years & 29 & 32,2 \\
Total & 90 & 100 \\
\hline Education & & \\
Bachelor & 10 & 11,1 \\
Diploma & 78 & 86,7 \\
High School & 2 & 2,2 \\
Total & 90 & 100 \\
\hline Work Experience & & \\
$<5$ years & 44 & 48,9 \\
5-10 years & 16 & 17,8 \\
$\quad>10$ years & 30 & 33,3 \\
Total & 90 & 100 \\
\hline
\end{tabular}

Respondents in this study amounted to 90 people, with 8 people $(8.9 \%)$ men and 82 people $(91.1 \%)$ women. Based on age, there were 11 people $(12.2 \%)$ respondents aged less than 25 years, 50 people (55.6\%) respondents aged 25-35 years, and 29 people $(32.2 \%)$ respondents aged over 35 years. Based on the formal education of the respondents, most of the respondents were educated D3, which was as many as 78 people
(86.7\%), while those who had S1 education were 10 people $(11.1 \%)$ and there were 2 people $(2.2 \%)$ respondents who had SPK education . Based on work experience, there were 44 people $(48.9 \%)$ respondents with less than 5 years work experience, 16 people $(17.8 \%)$ respondents with 5-10 years work experience, and 30 people $(33.3 \%)$ respondents with work experience of more than 10 years.

Table 4. Variable Motivation Frequency Distribution

\begin{tabular}{lcc}
\hline \multicolumn{1}{c}{ Statement } & Score & $\begin{array}{c}\text { Percentage } \\
(\%)\end{array}$ \\
\hline I feel comfortable with my current job. & 367 & 7,50 \\
\hline I feel satisfied with my current job. & 346 & 7,07 \\
\hline I get a salary that is in line with the workload. & 260 & 5,31 \\
\hline The award is given in accordance with what I do. & 273 & 5,58 \\
\hline My salary is enough for living & 255 & 5,21 \\
\hline
\end{tabular}




\begin{tabular}{lcc}
\hline My workload is lighter than the salary earned. & 208 & 4,25 \\
\hline My current workplace provides a good career path. & 307 & 6,27 \\
\hline My workplace supports me to develop myself & 334 & 6,82 \\
\hline I get the same opportunity with other employees in self development. & 337 & 6,88 \\
\hline $\begin{array}{l}\text { I get support for carrying out tasks in accordance with the professional } \\
\text { standards that I have. }\end{array}$ & 362 & 7,39 \\
\hline My current job is in suitable with the competencies that I have. & 364 & 7,43 \\
\hline I feel comfortable at work. & 359 & 7,33 \\
\hline I have a good relationship with colleagues. & 388 & 7,92 \\
\hline I'm easy to work with other people. & 386 & 7,88 \\
\hline I can face conflicts with colleagues. & 350 & 7,15 \\
\hline Total & 4896 & 100 \\
\hline Average [total score : $(15 \times 90)]$ & \multicolumn{2}{c}{3,627} \\
\hline
\end{tabular}

The statement with the smallest score is "My workload is lighter than the salary earned.", Which is 208 (4.25\%). The mean score for the motivation variable is 3.627 .

Table 5. Variable Training Frequency Distribution

\begin{tabular}{lcc}
\hline \multicolumn{1}{c}{ Statement } & Score & $\begin{array}{c}\text { Percentage } \\
(\%)\end{array}$ \\
\hline $\begin{array}{l}\text { Training on patient safety adds to my knowledge. } \\
\begin{array}{l}\text { The knowledge I gained from patient safety training was in accordance } \\
\text { with the work I did. }\end{array}\end{array}$ & 392 & 6,78 \\
\hline Patient safety training provides knowledge that suits my work needs. & 381 & 6,68 \\
\hline $\begin{array}{l}\text { The knowledge I got from patient safety training was useful in my } \\
\text { work. }\end{array}$ & 392 & 6,78 \\
\hline Training on patient safety adds to my skills. & 382 & 6,61 \\
\hline $\begin{array}{l}\text { The skills I gained from patient safety training were in accordance with } \\
\text { the work I did. }\end{array}$ & 380 & 6,58 \\
\hline Patient safety training provides skills that suit my work needs. & 373 & 6,46 \\
\hline The skills I get from patient safety training are useful in my work. & 376 & 6,51 \\
\hline I provide friendly service. & 400 & 6,92 \\
\hline I can be friendly to patients even though the workload is high. & 385 & 6,66 \\
\hline I give the same service to every patient. & 404 & 6,99 \\
\hline $\begin{array}{l}\text { Patient safety training makes me more responsible for providing } \\
\text { services. }\end{array}$ & 390 & 6,75 \\
\hline I prioritize patient safety in service. & 387 & 6,70 \\
\hline The main priority in my work is patient safety. & 388 & 6,72 \\
\hline Poor patients have the right to get the best service. & 362 & 6,27 \\
\hline Total & 5778 & 100 \\
\hline Average [total score : (15x90)] & 4,280 \\
\hline
\end{tabular}

The statement with the smallest score is " Poor patients have the right to get the best service.", Which is $362(6.27 \%)$. The

\section{Table 6. Variable Work Environment Frequency Distribution}

\begin{tabular}{lcc}
\hline \multicolumn{1}{c}{ Statement } & Score & $\begin{array}{c}\text { Percentage } \\
(\%)\end{array}$ \\
\hline Lighting at my workplace supports the work I do. & 357 & 6,97 \\
\hline My workplace is bright enough & 352 & 6,87 \\
\hline I feel comfortable with the temperature of the work room at this time. & 305 & 5,95 \\
\hline I feel the air circulation in my workplace is good. & 302 & 5,90 \\
\hline The temperature of the room in my workplace was as I expected. & 276 & 5,39 \\
\hline
\end{tabular}

mean score for the training variable is 4,280. 


\begin{tabular}{lcc}
\hline The air circulation in my workplace made me feel comfortable at work. & 295 & 5,76 \\
\hline I feel safe in doing my work. & 342 & 6,68 \\
\hline The security system at my workplace is quite good. & 321 & 6,27 \\
\hline I am sure of the level of security in the workplace at this time. & 310 & 6,05 \\
\hline I can work with fellow nurses. & 388 & 7,58 \\
\hline I can overcome conflicts with fellow nurses. & 372 & 7,26 \\
\hline I understand the information provided by other nurses. & 371 & 7,24 \\
\hline I can work with a doctor. & 378 & 7,38 \\
\hline I am happy to work with a doctor. & 377 & 7,36 \\
\hline I can understand the instructions given by the doctor. & 376 & 7,34 \\
\hline Total & 5122 & 100 \\
\hline Average [total score : $(15 \times 90)]$ & \multicolumn{2}{c}{3,794} \\
\hline
\end{tabular}

The statement with the smallest score is "The temperature of the room in my workplace is exactly what I expected.",
Which is $276(5.39 \%)$. The mean score for environmental variables is 3.794 .

Table 7. Variable Performance Frequency Distribution

\begin{tabular}{|c|c|c|}
\hline Statement & Score & $\begin{array}{l}\text { Percentage } \\
\quad(\%)\end{array}$ \\
\hline $\begin{array}{l}\text { I identify patients by paying attention to at least } 2 \text { things in the patient's } \\
\text { identity sheet. }\end{array}$ & 385 & 4,12 \\
\hline I always check the patient's bracelet before taking nursing action. & 387 & 4,14 \\
\hline $\begin{array}{l}\text { I gave medicine to the patient by first checking the patient's bracelet } \\
\text { name. }\end{array}$ & 397 & 4,25 \\
\hline I noted the instructions given and the time. & 398 & 4,26 \\
\hline I repeat the instructions given by telephone. & 381 & 4,07 \\
\hline $\begin{array}{l}\text { I asked the listener to repeat the results of the laboratory that I reported } \\
\text { by telephone. }\end{array}$ & 366 & 3,91 \\
\hline I always record instructions given by telephone. & 383 & 4,10 \\
\hline I asked about drug allergies before giving medication to patients. & 376 & 4,02 \\
\hline I checked an allergic reaction for all the drugs given. & 391 & 4,18 \\
\hline I did a separation in the storage of drugs that resembled the name. & 395 & 4,22 \\
\hline I did a separation in the storage of drugs that resembled the packaging. & 385 & 4,12 \\
\hline I checked all documents before the patient underwent surgery. & 405 & 4,33 \\
\hline $\begin{array}{l}\text { I ensure the consistency of the data in the medical record before the } \\
\text { patient undergoes surgery. }\end{array}$ & 402 & 4,30 \\
\hline $\begin{array}{l}\text { I made sure the patient's informed consent was appropriate before the } \\
\text { patient underwent surgery. }\end{array}$ & 407 & 4,35 \\
\hline $\begin{array}{l}\text { Informed consent for patients who will undergo surgery is always done } \\
\text { in writing. }\end{array}$ & 412 & 4,41 \\
\hline I washed my hands after contact with patients. & 411 & 4,40 \\
\hline I washed my hands before contacting patients. & 402 & 4,30 \\
\hline I washed my hands with the right hand washing technique. & 402 & 4,30 \\
\hline I washed my hands after treating the patient & 403 & 4,31 \\
\hline I did a repeat assessment of patients who fell. & 376 & 4,02 \\
\hline I do repeated assessment in patients at risk of falling. & 370 & 3,96 \\
\hline $\begin{array}{l}\text { I always identify the risk of falling in patients who have been treated } \\
\text { for more than } 1 \text { week. }\end{array}$ & 366 & 3,91 \\
\hline $\begin{array}{l}\text { I made a Patient Safety Incident Report when there were patients who } \\
\text { fell. }\end{array}$ & 367 & 3,93 \\
\hline $\begin{array}{l}\text { I do not need to make a Patient Safety Incident report if there are } \\
\text { patients who have just fallen } 1 \text { time. }\end{array}$ & 383 & 4,10 \\
\hline Total & 9350 & 100 \\
\hline Average [total score : $(24 \times 90)]$ & & , 329 \\
\hline
\end{tabular}


The statement with the smallest score is "I ask the listener to repeat the results of the laboratory that I reported by telephone." And "I always identify the risk of falling in patients who have been treated for more than 1 week.", Ie 366 $(3.91 \%)$. The mean score for the performance variable is 4.329 .

Tabel 8. Variable Analysis Based on Category

\begin{tabular}{ccc}
\hline Variable & Average & Category \\
\hline Motivation & 3,627 & High \\
\hline Training & 4,280 & Very high \\
\hline Work Environment & 3,794 & High \\
\hline Performance & 4,329 & Very high \\
\hline
\end{tabular}

The highest average is obtained from the performance variable, which is equal to 4.329, while the lowest average is motivation, amounting to 3.627. Based on grouping categories, motivation and environment are in the high category, while training and performance are in the very high category.

The correlation analysis by using significance value $<0.05$ showed that there is a correlation between motivation and training, motivation and environment, and between training and the environment. The magnitute showed a strong correlation for each variables.

To analyze the causal relationship (influence) between Motivation, Training, and Environment on Nurses' Performance in Patient Safety at Public Hospital, an analytical method was used called Path Analysis. The path equation model resulted in this research is $\mathrm{Y}=$ $0,292 \mathrm{X} 1+0,320 \mathrm{X} 2+0,295 \mathrm{X} 3+\varepsilon$. The path equation shows a positive coefficient value, meaning that the motivation variable (X1), training (X2), and environment (X3) will improve performance $(\mathrm{Y})$. Based on the path equation, the path coefficient $\mathrm{X} 1$ is 0.292 , the path coefficient $\mathrm{X} 2$ is 0.320 , and the path coefficient of $X 3$ is 0.295 . If only considering motivation variables and training and environment variables are considered constant, then each addition of one unit of motivation variable will increase performance by 0.292 units. If the training variable is calculated and the motivation and environment variables are considered constant, then each addition of one training unit variable will increase the performance by 0.320 units. Likewise, if environmental variables are taken into account and motivation and training variables are considered constant, then each addition of one unit of environmental variable will increase the performance by 0.295 units.

The coefficient of determination (R2) in this path equation is 0.620 , which means that $62 \%$ of the performance variables are influenced by variables of motivation, training, and environment.

Based on the calculation, it was found that the direct effect of motivation on performance was $8.5 \%$, the direct effect of training on performance was $10.2 \%$, and the direct effect of the environment on performance was $8.7 \%$. It is known that motivation has an indirect influence on performance through training with an influence of $5.9 \%$ and motivation has an indirect influence on performance through the environment with an influence of $6.3 \%$. Training provides an indirect influence on performance through motivation with an influence of $5.9 \%$ and gives an indirect influence on performance through the environment with an influence of $5.7 \%$. The environment has an indirect influence on performance through motivation with an influence of $6.3 \%$ and gives an indirect influence on performance through training with an influence of $5.7 \%$. Based on the calculation, the influence of 
motivation on performance was obtained by $20.7 \%$, the effect of training on performance was the largest, namely $21.8 \%$, and the influence of the environment on performance was $20.7 \%$. The result of hypothesis test showed that there is a significant effect of nurse

\section{Discussion}

The results of the study on the motivation of nurses at the Public hospital described good results in the high category. This shows that the need for achievement, need for power, and the need for affiliation for nurses in general has been well fulfilled. Nurses feel they have received appreciation and satisfaction in work, the opportunity to develop themselves in their profession, and have a good relationship with their coworkers. However, based on the results of the questionnaire there still appears to be the lowest score on questions that assess salary and workload.

Based on motivation theory, salary and workload are included in the needs of achievement, namely work satisfaction and respect for work performance. However, it should also be considered that the salary or ability to fulfill living needs also depends on the surrounding economic situation. To increase motivation related to salary and workload, it can be done by increasing salaries or reducing workload. Public hospital as a government agency has salary standards that follow existing regulations, in contrast to private institutions which can issue more varied policies. Therefore, increasing motivation regarding salary and workload can be done by reducing the workload. Reduction of workload can be done not only by reducing the amount of work that must be done, but it can also be achieved by increasing efficiency in completing work that can be done by providing training and environmental arrangements that are appropriate to the needs of nurses. motivation, training, work environment, and also simultaneus effect of those variable on nurse performance in patient safety at Public Hospital.

The results of the research on the training of nurses at the Public hospital illustrate the excellent results in the very high category. This shows that the training conducted by Public Hospital has fulfilled the dimensions of knowledge, skills and attitudes according to what is needed. In addition to getting skills from the training held, nurses are also able to provide patient-friendly services. However, based on the results of the questionnaire there still appears to be the lowest score on questions that assess service delivery in patients who are unable.

Based on training theory, these problems are part of the attitude, namely responsibility for service and friendliness. The provision of nondiscriminatory services is the responsibility of the hospitals listed in the Act. To increase the responsibility of service and hospitality especially for patients who are not able, training can be carried out that not only focuses on patient safety standards, but also on ethics in health services. An example of training to achieve this goal is empathy training.

The results of the study on the work environment of nurses at the Public hospital described good results in the high category. This shows that the work environment, both physical and nonphysical at Public Hospital has been very good. Lighting, air circulation and security systems are considered good enough. In addition, the working atmosphere described by the working relationship between all nurses and doctors is also good. However, based on the results of the questionnaire there still appears to be the lowest score on 
questions that assess room temperature and air circulation.

Room temperature and air circulation are things that are classified in the physical environment. The state of the work environment related to temperature and air circulation is closely related to Public hospital as a national reference center for the health of respiration because respiration itself is strongly associated with conditions of temperature and air circulation. Environmental problems related to temperature and air circulation need serious attention because they have the potential to cause occupational diseases related to respiratory health. Efforts to improve the physical environment related to temperature and circulation can be done by involving the field of Occupational Health and Safety (K3), namely by conducting risk identification and evaluation to determine the repairs that need to be done.

The results of the study on the performance of nurses at the Public hospital illustrate the excellent results in the very high category. This shows a positive thing in patient safety at Public hospital. Patient safety standards that have been made in the form of patient identification standards, effective communication, drug administration, safety of surgical procedures, infection prevention and control, and prevention of falling patients have been able to be received and implemented properly by nurses. However, based on the results of the questionnaire there still appears to be the lowest score on questions that assess the fall in patient standards and repetition of laboratory results by telephone.

Reporting about patient falls is part of the standard for preventing patients from falling, while repetition of laboratory results or readbacks is part of effective communication standards. Problems with prevention standards for falling patients can be caused by the fact that these standards have not become a habit of culture in the hospital environment, whereas the existence of effective communication problems especially regarding readbacks can be caused by existing and not accustomed culture to repeating the results read. To make improvements in these standards, training and supervision can be carried out that focuses on the two standards.

Based on the results of the bivariable correlation test between motivation and performance, a strong correlation was found. This means that changes in motivation values will affect performance. Based on path analysis, the results showed that motivation had a direct influence $(8.5 \%)$ and indirect effects through training variables $(5.9 \%)$ and environment $(6.3 \%)$ on performance. Increased motivation can be done by paying attention to the compensation and workload of nurses, opportunities to develop themselves, and good relationships with colleagues. In this study, it was found that motivation problems were in the need of achievement, so it was necessary to pay attention to meeting the needs of each employee, especially nurses.

Based on the results of the bivariable correlation test between training and performance, a strong correlation was found. This means that changes in training values will affect performance. Based on path analysis, results were obtained stating that the training had a direct effect $(10.2 \%)$ and indirect effects through motivation variables $(5.9 \%)$ and environment $(5.7 \%)$ on performance. Good training can be carried out in accordance with the needs of the work to be carried out by nurses as well as emphasis on aspects of hospitality to patients. The results of this study are an evaluation of the patient safety training that has been carried out and become an upcoming training planning material.

Based on the results of the bivariable correlation test between the environment and the performance obtained a strong 
correlation. This means that changes in environmental values will affect performance. Based on path analysis, results were obtained stating that the environment had a direct influence $(8.7 \%)$ and indirect effects through motivation variables $(6.3 \%)$ and training $(5.7 \%)$ on performance. Environmental improvement can be done by paying attention to physical and non-physical aspects. The improvement of the physical environment is specifically related to occupational health and safety. By creating a good work environment, hospitals will benefit from increasing performance and preventing the risk of losses caused by health and safety issues.

Based on the results of the bivariable correlation test between the independent variables (motivation, training, environment) and the dependent variable (performance) there was a strong correlation. This means that changes in the value of each of the independent variables have a strong correlation with changes in performance. In addition, the results of the correlation test between independent variables also obtained a strong correlation for each variable. Therefore, changes from one independent variable will affect changes in the other independent variables and also affect changes in performance. Based on this, improvements to motivation, training, or the environment will have a significant impact on other variables and performance. This is also in accordance with the theory which states that each variable of motivation, training, and environment influences performance.

Based on path analysis, results were obtained stating that motivation, training, and the environment together had a positive effect on performance. This means that positive changes in motivation, training, and the environment will have a positive impact on nurse performance. Each independent variable has an indirect effect through other independent variables on performance. The biggest total influence is training with a value of $21.8 \%$, while motivation and environment are $20.7 \%$ respectively. This is also in accordance with the results of the calculation of the coefficient of determination of the smallest training variable, which is 0.465 compared to the coefficient of the motivation variable (0.504) and environment (0.492). Based on this, improving the performance of nurses in patient safety priority can be done by improving or improving training that is appropriate for patient safety. However, motivation and environment are also factors that can be prioritized as well because the total influence is not much different from training.

In making improvements in the management field, of course, support and cooperation from top, middle, and lower management is needed. Based on the theory of patient safety, hospital management is on the blunt end, and health workers are on the sharp side (sharp end). Systems including motivation, training, and the environment are things that affect the performance of health workers. A bad system increases the risk of unexpected events, while a good system will minimize the risk of unexpected events. In addition, with a good system, the possibility of latent conditions will be smaller.

Nurses' performance standards in the safety of patients in Public hospitals that have been based on internationally recognized guidelines have been successfully socialized and carried out by existing nurses. The successful implementation of patient safety standards in the field of nursing can be an example for other hospitals to improve and / or implement patient safety standards that follow internationally recognized guidelines.

Another thing to note is that in this study only $62 \%$ of the performance variables were influenced by variables of 
motivation, training, and environment. Therefore, there are still $38 \%$ of performance variables that are influenced by other variables. Other variables that are expected to influence performance especially in hospitals include the different characteristics of patients, the number of standard operating procedures for varied services, differences in perceptions and culture of patient safety, and the involvement of various fields in implementing patient safety in hospitals.

\section{Conclusion}

1. Motivation of nurses at Public hospital is currently in a good category, but problems still arise in terms of salary and workload.

2. The training of nurses at Public Hospital is currently in a very good category, but problems are still found in terms of service responsibility and friendliness in poor patients.

3. The work environment of nurses at Public hospital is currently in a very good category, but problems still arise in terms of room temperature and air circulation.

4. The performance of nurses at Public hospital is currently in a very good category, but problems are still found in falling patient prevention standards and effective communication, especially in repetition of laboratory results by telephone.

5. Nurse motivation has a positive and significant effect on nurse performance in patient safety at Public hospital

6. Nurse training has a positive and significant effect on nurse performance in patient safety at Public hospital

7. Nurse's work environment has a positive and significant effect on nurse's performance in patient safety at Public hospital

8. The motivation, training, and work environment of nurses together have a positive and very significant effect on nurse performance in patient safety at Public hospital.
Based on those conclusions, we can suggest as follow:

1. To increase motivation in terms of salaries and workloads, workload reduction can be done considering that salary factors are difficult to intervene. Reduction of workload can be done not only by reducing the amount of work that must be done, but it can also be achieved by increasing efficiency in completing work that can be done by providing training and environmental arrangements that are appropriate to the needs of nurses.

2. Problems in terms of service responsibility and friendliness in poor patients can be reduced by providing ethics-focused training, such as empathy training.

3. In overcoming problems related to the physical environment related to temperature and circulation, it should involve the field of Occupational Health and Safety (K3), namely by conducting risk identification and evaluation to determine the improvements that need to be made.

4. The performance of nurses at Public hospital is currently in a very good category, but problems are still found in falling patient prevention standards and effective communication, especially in repetition of laboratory results by telephone. To make improvements in these standards, training and supervision can be carried out that focuses on the two standards.

5. Increased motivation can be done by paying attention to compensation and workload of nurses, opportunities to develop themselves, and good relationships with colleagues. Therefore, it is best to evaluate the compensation system and the opportunity to develop themselves.

6. The results of this study are evaluations of patient safety training that have been carried out and can be used as material for future training planning. 
7. In carrying out environmental improvements, especially the physical environment related to occupational health and safety, it is necessary to identify each inpatient ward to get a more specific picture for each workplace.

8. The motivation, training, and work environment of nurses together influence the performance of nurses in patient safety at Public hospital. However, in this study only $62 \%$ of performance variables were influenced by variables of motivation, training, and environment. Therefore, research is still needed to determine the effect of other variables not examined in this study.

\section{References}

Dekker, Sydney. 2016. Patient Safety: A Human Factor Approach. CRC Press.

Dessler, Gary. 2017. Human Resource Management. Fifteenth. Pearson.

DiCuccio, Margaret Hardt. 2015. "The Relationship Between Patient Safety Culture and Patient Outcomes: A Systematic Review." Journal of Patient Safety 11 (3): 135-42. https://doi.org/10.1097/PTS.000000 0000000058.

Elsheikh, Ahmed Mohamed, Mohammed Abdullah AlShareef, Bassem Salah Saleh, and Muhammad Abdullah Yassin El-Tawansi. 2017. Assessment of Patient Safety Culture: A Comparative Case Study between Physicians and Nurses. Business Process Management Journal. Vol. 23. https://doi.org/10.1108/BPMJ-022017-0029.

Gunawan, Joko, and Yupin Aungsuroch. 2015. "Indonesia Health Care System and Asean Economic Community." International Journal of Research in Medical Sciences 3 (7): 1571-77. https://doi.org/10.18203/23206012.ijrms20150231.

Harrison, Reema, Adrienne Wai Seung
Cohen, and Merrilyn Walton. 2015. "Patient Safety and Quality of Care in Developing Countries in Southeast Asia: A Systematic Literature Review." International Journal for Quality in Health Care 27 (4): 240-54. https://doi.org/10.1093/intqhe/mzv0 41.

Langton, Nancy, Stephen P. Robbins, and Tomothy A. Judge. 2016. Organizational Behaviour: Concept, Controversies, Applications.

Ma, Chenjuan, Danielle M. Olds, and Nancy E. Dunton. 2015. "Nurse Work Environment and Quality of Care by Unit Types: A CrossSectional Study." International Journal of Nursing Studies 52 (10): 1565-72.

https://doi.org/10.1016/j.ijnurstu.20 15.05.011.

Olds, Danielle M., Linda H. Aiken, Jeannie P. Cimiotti, and Eileen T. Lake. 2017. "Association of Nurse Work Environment and Safety Climate on Patient Mortality: A Cross-Sectional Study." International Journal of Nursing Studies 74 (June): 155-61. https://doi.org/10.1016/j.ijnurstu.20 17.06.004.

Robbins, S. P., DeCenzo, D. A., and Coulter, M. 2017. Fundamentals of Management: Management Myths Debunked! Pearson. Vol. 10th ed. https://doi.org/10.1007/s00405004-0884-z.

Sommers, Christine L., Tarihoran DE, Sandra Sembel, and H M Tzeng. 2018. "Perceived Images and Expected Roles of Indonesian Nurses." Nursing Open, no. November 2017: 1-6. https://doi.org/https://doi.org/10.10 02/nop2.156.

Sutarto, Agus, Hermanu Joebagio, and Pawito. 2016. "Relationship Between Motivation, Competence, Workload, and Nurse Performance , at Dr . Soediran." Journal of Health Policy and Management 1 (2): 78- 
94.

https://doi.org/10.26911/thejhpm.2 016.01.02.03.

Vansant, Brian. 2016. "Institutional Pressures to Provide Social Benefits and the Earnings Management Behavior of Nonprofits: Evidence from the U.S. Hospital Industry." Contemporary Accounting Research 33 (4): 15761600. https://doi.org/10.1111/19113846.12215.

Wayne, Cascio, and Aguinis Herman. 2017. Applied Psychology in Human Resource Management. Seventh. Vol. 91. Pearson.

Xie, Jian fei, Si qing Ding, Zhu qing Zhong, Sai nan Zeng, Chun xiang Qin, Qi feng Yi, Li na Gong, and Jian da Zhou. 2017. "A Safety Culture Training Program Enhanced the Perceptions of Patient Safety Culture of Nurse Managers." Nurse Education in Practice 27: 128-33. https://doi.org/10.1016/j.nepr.2017. 08.003 .

\section{Biographies}

\section{Fushen}

Graduated from Faculty of Medicine Universitas Indonesia as Medical Doctor in 2009, received both Master Degree in Health Law from Universitas Padjajaran and Master Degree in Management from Universitas Pasundan in 2012. Fushen has been working as hospital management consultant since 2012, has previous worked in National Cardiovascular Center Harapan Kita. Currently working as lecturer in Akademi Kesehatan Swakarsa Jakarta and guest lecturer in Universitas Kristen Krida Wacana.

\section{Meylona Verawaty Zendrato}

Graduated from Universitas Sumatera Utara for Diploma and Bachelor of Nursing in 2012. Received Master Degree of Nursing from University of Indonesia majoring in Leadership and Management of Nursing in 2018. She is currently a lecturer at Swakarsa School of Nursing.

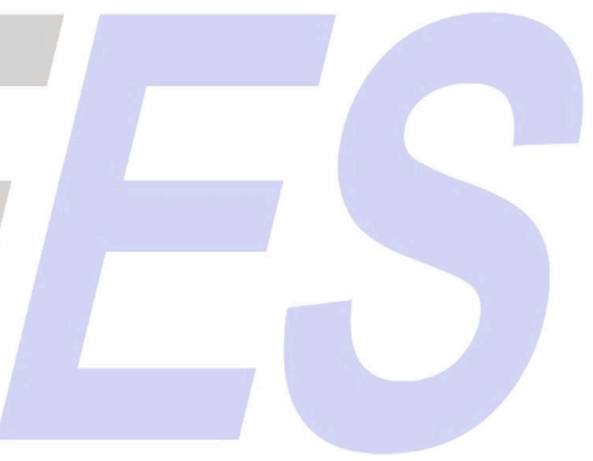

